\title{
Sciendo
}

DOI:10.1515/sspjce-2020-0021

\section{Investigation of the use of various materials for the construction of an enthalpy exchanger}

\author{
Pavol Kozák, Danica Košičanová \\ Technical University of Košice, Slovakia \\ Civil Engineering Faculty, Institute of Environmental Engineering \\ e-mail: pavol.kozak@gmail.com, danica.kosicanova@tuke.sk
}

\begin{abstract}
Considering the current gradual depletion of non-renewable primary sources, it is necessary to address the reduction of energy consumption in ventilation and air conditioning systems. Although heat recovery alone reduces the energy intensity of these systems, if moisture recovery is considered as well, the contribution in reducing energy consumption is significant. These are mainly the devices designed primarily for spaces where people stay permanently, which do not allow large fluctuations in temperature and humidity. In cooperation with the manufacturer of heat recovery exchangers, we determined our own method of comparing different types of materials that could be used to design an exchanger which would also allow moisture recovery. These results in a significant reduction in energy consumption used to humidify the air in ventilation and air conditioning systems. It is one of the possible ways how to compare individual samples that are being measured. This article primarily deals with the comparison of three different types of materials, out of the total number of twelve measured samples.
\end{abstract}

Key words: enthalpy exchanger, permeability, moisture recovery, air handling unit, ventilation and air conditioning unit

\section{Introduction}

The current global situation, rapid economic development and industrial growth of individual countries result in accelerated depletion of primary energy sources, which threatens the future of any life on our planet. This state is simply not sustainable. Primary energy sources are not renewable and therefore, it is in the interest of each and every one of us to look for a solution how to prevent it, how to reverse this situation, slow it down or stop it completely. People cannot pretend it is not their responsibility. All these primary sources are being used for human needs; therefore, everyone should have their energy consumption under control and try to use energy as economically as possible. It basically does not matter if it is a household, a residential agglomeration, an industrial or agricultural operation. Attention must be paid to the 
sustainability aspect of primary energy sources. In many cases, humanity needs to learn how to save energy. It has a huge impact on our future and the future of the next generations.

The primary legislative document for the energy performance of buildings is [1]. It defines the minimum requirements for new and renovated buildings, requirements for energy certification, requirements for heating and air conditioning systems control, and electromobility. There should be a focus on comparing the primary energy consumption and the method of evaluating its accuracy and evaluation errors [2, 5]. Optimization of primary energy consumption in HVAC systems is of great importance. There is a significant attention on the research in this area $[3,4,6]$.

The potential savings when using model predictive control (MPC) to monitor temperature and humidity are discussed in [7].

Research and development in the energy consumption sector is moving in the direction of a search for possibilities to use renewable energy sources as much as possible. This applies not only to ventilation and air conditioning systems, but almost too all the areas that need energy sources. The goal is to gradually build "green buildings" [8].

Cho, K., Cho, D., and Kim, T. researched the reduction of electricity consumption in the ventilation and recuperation unit. The results of the experiments conducted in this study demonstrated that the bypass and room control modes of HRVS can result in an annual fan energy saving up to $\sim 10.76 \%-61.84 \%$ [9].

By using renewable resources, reducing energy consumption, and increasing the efficiency of ventilation and air conditioning equipment, people could contribute to the preservation of the earth's primary energy sources for the future generations. The use of renewable energy sources has the greatest potential in this area, be it solar, water, wind, or air energy. One of the possibilities is to store thermal energy and to use it subsequently [10].

Another view on reducing energy consumption is the economic aspect, as energy prices are constantly rising, and the overall tendency is even less favorable. From this point of view, it can be assumed that if the society wants to maintain the same standard of living in the future as it currently enjoys, it will be much more financially demanding in the future. Therefore, it is appropriate to invest in renewable energy sources already in the present. In many countries these are already supported by the state subsidies. In this way, low operating costs for energy can be achieved in the future and at the same time, the environment would not be burdened.

Technological progress is currently focused on product improvement and work efficiency in the production process. Last but not least, there is an effort to achieve automation of production processes, robotization and minimization of errors, which results in increased quality and efficiency of individual products. The aim of the manufacturers is to minimize production costs, while maintaining the highest possible production quality. Production processes become fully automated, with minimal human intervention. By minimizing the human labor the production process becomes more error-free, reliable, faster and efficient. Robotization and automation ultimately bring manufacturers not only an increase in production capacity, simplification of the entire production process (from design, through production process itself, to dispatch), but also simplification of warranty and post-warranty service of individual products. Bar codes and QR codes speed up the identification of equipment and components, which also has a significant impact on the production process. 
Based on the Paris Agreement under the United Nations Framework Convention on Climate, and the subsequent European Green Deal currently being negotiated, [11] the European Union has set a goal to achieve climate neutrality by 2050. The Paris Agreement of 2015 requires all the signatories to commit to reducing greenhouse gas emissions. Every five years, each signatory shall increase the obligations under this Agreement, except for developing countries for which a transitional period applies. It is in developing countries where the fulfillment of the commitments is the most difficult. However, a tiny developing country, Bhutan, which was already carbon neutral, or rather, carbon negative in 2009, can serve as an example for all the countries in the world. With the help of its natural resources, this small country manages to sequester three times more $\mathrm{CO} 2$ per year than it produces [12]. It is an example worth following. Achieving this neutrality will include a transformation of the European society and economy, but in a fair and effective manner. This agreement assumes that in the second half of the century, European countries will produce only as much emissions as nature is able to sequester, thus achieving carbon neutrality.

Currently, the European Parliament intervenes in the field of ventilation and air-conditioning in a rather significant way by the means of the European Commission's regulation No. 1253/2014 from 7 July 2014, implementing the directive 2009/125/ES of the European Parliament and of the Council [13] concerning the eco-design of ventilation units. This regulation significantly increases the energy efficiency of the ventilation equipment meeting the requirements of this directive. Ventilation devices receive energy labels, based on which they can be compared in a relevant way. Each device must indicate under which operating parameters it complies with the afore-mentioned directive.

Manufacturers are striving to come up with the most economical ventilation and air conditioning systems. They invest a lot of money in research and development, thus trying to increase the efficiency of their devices.

The analysis of topics in heating, ventilation and air conditioning is presented in [14]. Energysaving fans exhaust air heat recovery devices, heat pumps, high-efficiency heat exchangers, humidification and dehumidification units and various filtration devices are installed in the equipment. The casing of the device itself is designed and manufactured to have minimum heat loss and the greatest possible tightness. All these measures increase the efficiency of individual devices. The aim is also to achieve the smallest possible error rate of individual HVAC systems, for example in the use of automated fault detection and diagnostics. (The application of automated fault detection and diagnostics (FDD) under HVAC predictive maintenance programs requires the development of simulation models able to accurately compare the faulty operation with respect to nominal conditions) [15].

Each of these components is subject to continuous research and development, whether on an academic or competitive basis. This results in high-efficiency devices with minimal energy consumption. It should be everyone's goal to ensure comfort of the environment for which the air handling unit is designed.

Much attention is being paid to research in this area. A possible increase in the efficiency of HVAC systems is mentioned in $[16,17]$.

The measurement and mutual comparison of two enthalpy exchangers is discussed in [18].

Zhang focuses on a specific laboratory space and possible savings in energy consumption by 
using an HPHX (Heat Pipe Heat Exchanger) [19, 20].

An alternative to a countercurrent enthalpy exchanger is a rotary exchanger. Its analysis can be found in $[21,22]$.

Most units are designed and manufactured for use in areas where people move and breathe the air treated in these devices. Therefore, it is paramount to approach the research, development, production, installation, operation and maintenance of these devices thoroughly. Several parameters affecting the thermal comfort in space have been addressed in [23].

Indoor air quality based on $\mathrm{CO} 2$ concentration depending on ventilation is investigated in [24]. Lowering of indoor air quality and subsequent recommendation of forced ventilation with heat recovery is discussed in [25].

\section{Experiment}

Humidity can be expressed in several ways [26].

- Absolute air humidity, $\mathrm{a}=\mathrm{gd}$. It is the actual water vapor density in the air $\left(\mathrm{kg} / \mathrm{m}^{3}\right)$

- Partial water vapor pressure, pd. It is most frequently determined by measuring with a dry and wet thermometer

- Relative humidity, Rh. It characterizes the degree of air saturation (\%)

- Specific humidity, X. It is the weight of water vapor per $1 \mathrm{~kg}$ of dry air $(\mathrm{kg} / \mathrm{kg})$

- Dew point temperature - the temperature at which the air is saturated when being cooled by water vapor

- The wet bulb temperature, tm. It is the equilibrium temperature at which the heat needed to evaporate water from a wet surface is supplied from the air. It is used to measure air enthalpy.

Relative humidity is an important parameter not only when expressing thermal comfort in interiors, but it is also an important parameter from the hygienic point of view. When assessing the thermal state of the environment according to the air temperature, humidity can be ignored only if the relative humidity in summer is less than $60 \%$. At higher relative humidity, the great partial pressure of water vapor makes it difficult to evaporate sweat, which results in disturbed thermal comfort [27]. Maintaining humidity under optimal conditions is, therefore, very important. In Slovakia, the binding limits valid for certain types of operations are defined in particular in [28] [29].

Measuring of permeability can also be done according to the norm ASTM E96-00 [30], which is experimentally elaborated in detail [31]. For this reason we chose our own methodology of measuring and evaluating the possible use of different types of materials in the research of moisture transfer by different materials, as well as their possible use in an enthalpy exchanger, i.e. an exchanger enabling the transfer of heat energy and moisture. There are many materials that could be used to build an enthalpy exchanger; however, considering the achieved results from measurements, not all of them are suitable. The selection of the measuring set took a long period of time, during which we, together with Atrea Company, tried to come up with a suitable methodology for comparing samples. The most suitable one seemed to be the comparison of the material of the same size, in the same (or comparable) boundary conditions.

The measurements took place in the span of one year, from May 2019 to June 2020, at not exactly regular intervals. The measurements were carried out in the laboratory of Atrea

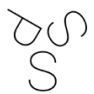


Company, which provided measuring instruments, premises and valuable advice both in the construction of the measuring set itself and in the evaluation of individual values. However, due to the geographical distance from Atrea, which is based in Jablonec nad Nisou, Czech Republic, several measurements were carried out at home, since the measuring set is easily portable and takes a short time to prepare.

A modified aquarium served as a measuring set. It was gradually modified and improved in order to obtain the most accurate data from individual measurements. Also, the size and shape of the opening for the measured sample was gradually changed up to the final circular crosssection with a diameter of $100 \mathrm{~mm}$, which subsequently allows easier calculation of the results. The result of the measurements determined the specific water vapor permeability of individual samples.

The main component of the measuring apparatus, "the aquarium", consists of a glass square container with an attached fitted, tightly sealed stainless steel frame with a rubber seal for fitting the cover with the measured sample. The container is closed with a tight double cover made of stainless steel, where the measured sample is installed between two stainless steel plates. The overall dimensions of the container including the sheet metal extension are $300 \mathrm{x}$ $200 \times 260 \mathrm{~mm}$. The net weight of the measuring set is $4190 \mathrm{~g}$. The tightness of the sample is ensured by a polymer-based sealant without solvents and isocyanates used in the automotive industry for car bodies. The plates with the measured sample are screwed together and the screws themselves are sealed again after tightening. The cover is placed on the aquarium and fastened with plier clamps. In addition, because of the weighing method of the whole apparatus as well as for better tightness, small wooden prisms are attached transversely along the shorter side of the aquarium. On these, a board containing assembly accessories is placed during weighing. A visual check confirms that it is fitted correctly with the container. At the beginning of measurements, a combination humidity and temperature sensor in the aquarium was also used. A 100\% relative humidity is assumed during the experiment. In addition, to increase the efficiency of the measurement, a small fan from a computer with a safe voltage of $12 \mathrm{~V}$ DC was installed in the set. This ensures the convection of water vapor during the experiment needed to bring the state in the aquarium closer to real conditions. The fan is mounted in a plastic baffle so that the flow is directed directly to the measured sample. The heater is a standard aquarium heater with a power of $50 \mathrm{~W}$ and a thermostat with a $230 \mathrm{~V}$ power supply, purchased in an aquarium shop. The accuracy of the thermostat on the immersion heater was in conflict with the actual water temperature, and this temperature difference was changing. Therefore, an additional informative immersion mercury thermometer was used to determine when the system is in a stabilized state with the ambient temperature, and thus it is possible to start measurement.

The measurement itself is performed as follows: the aquarium is filled with water so that the immersion electric heater itself is immersed. The sample is tightly attached in the opening in the cover which had been precisely cut out on a CNC machine, the container is closed, and all the mechanical joints are sealed with a sealant which is used in the automotive industry to seal car body parts. Subsequently, the water is heated to $23 \mathrm{C}$. This temperature is considered as a boundary condition in the steady state of the apparatus at the beginning of the measurement. Then, the measuring set is weighed with all the components: two small wooden prisms are placed on the cover of the apparatus. On these prisms, a plate made of PIR panel UNILIN for smart living is placed. This serves as a mechanical protection of the measured sample during weighing, and at the same time, as a surface on which the fixed assembly accessories are 
placed. All cable wires from the built-in temperature and humidity sensors, the power line and the fan power supply, as well as the power supply of the electric immersion heater are placed on this PIR plate. The set- up is weighed ten times on a calibrated scale placed on a solid horizontal base, in our case a desk.

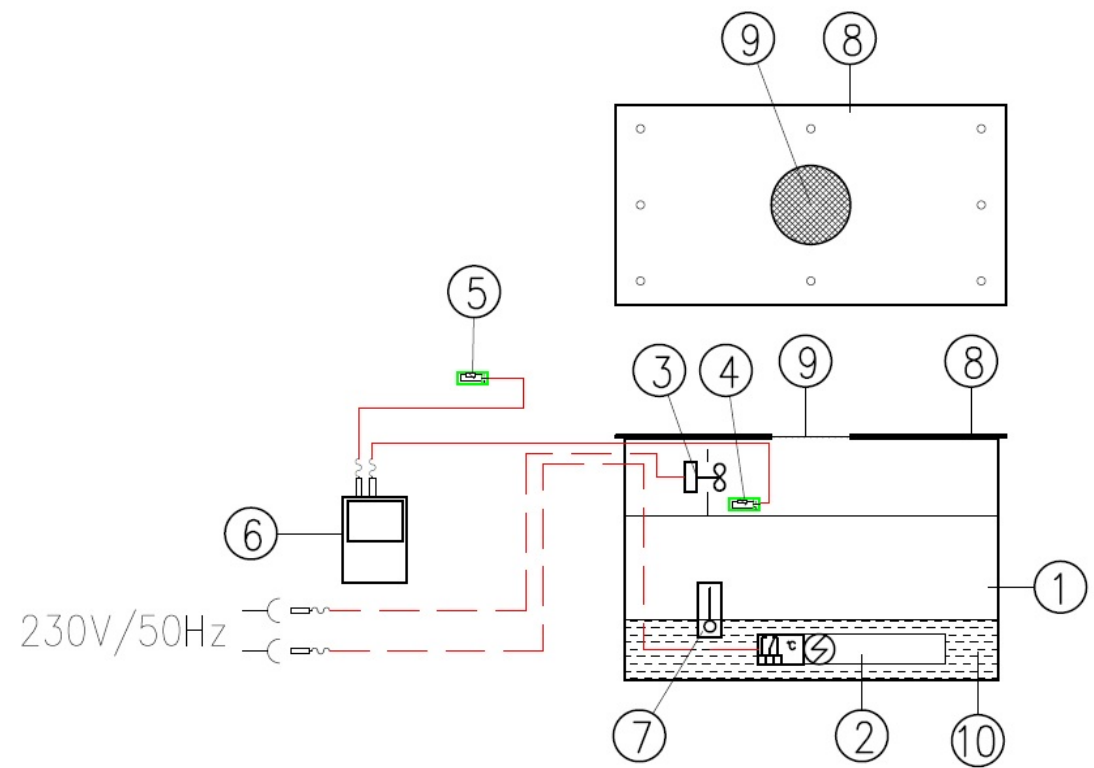

Figure 1: Measuring assembly scheme

\begin{tabular}{|c|c|c|}
\hline (1) & E- & $\begin{array}{l}\text { aquarium } \\
\text {-the main componet of the assembly }\end{array}$ \\
\hline (2) & (100) & $\begin{array}{l}\text { heater with thermostat, } 230 \mathrm{~V} / 50 \mathrm{~Hz}-50 \mathrm{~W} \\
\text { - water temperature adjustment in the assembly }\end{array}$ \\
\hline (3) & प्-8 & $\begin{array}{l}\text { AIREN Fan RedWings } 4012 \mathrm{~V} \text { DC } \\
\text { - ensuring air convection in the assembly }\end{array}$ \\
\hline (4) & 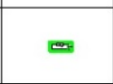 & $\begin{array}{l}\text { temperature sensor /AHLBORN ALMEMO } 2690 \text { instrument's probe } \\
\text { - measuring the air temperature in the aquarium }\end{array}$ \\
\hline (5) & $\approx$ & $\begin{array}{l}\text { temperature and humidity sensor /AHLBORN ALMEMO } 2690 \text { instrument's probe } \\
- \text { - measuring the air temperature and ambient moisture }\end{array}$ \\
\hline (6) & & $\begin{array}{l}\text { AHLBORN ALMEMO } 2690 \text { measuring instrument } \\
\text { - logging the temperature and humidity from the sensors in the assembly }\end{array}$ \\
\hline (7) & 近 & $\begin{array}{l}\text { informative submersible mercury thermometer } \\
\text {-checking the steady state of the assembly before the start of the measurement }\end{array}$ \\
\hline (8) & $\square$ & $\begin{array}{l}\text { cap with an opening for the measured sample } \\
\text { - the measured sample has been tightly attached here, joints sealed }\end{array}$ \\
\hline (9) & & $\begin{array}{l}\text { measured sample } \\
\text {-individual measured samples, sealed with putty }\end{array}$ \\
\hline (10) & & $\begin{array}{l}\text { water } \\
\text {-tap water heated to the ambient tempterature }\end{array}$ \\
\hline & -- & $\begin{array}{l}\text { cable wiring } \\
\text {-full line: sensor wiring, interrupted line: power supply }\end{array}$ \\
\hline
\end{tabular}

Figure 2: Table of the measuring assembly components

Each weighing takes place only after the water level has stabilized, which is monitored 
visually. Then the measuring system is reconnected to the electric heater, the temperature and humidity sensors are connected to the measuring instrument and the fan adapter is switched on. The set is then left in a room with minimal fluctuations in ambient temperature, removed from the scale, placed on a flat surface, with heating on. The measurement time was dependent on the free time available. Some samples were measured for several hours, some for several days. The measurement time does not directly affect the specific permeability as can be seen in the graphical evaluation. At the end of the experiment, the measuring set is disconnected from the power supply, the sensors are disconnected and placed again on the PIR board on the wooden prisms, and weighed again ten times. The result is recorded. We then define the difference in humidity over the period of time on the specific area as the specific water vapor permeability in $\mathrm{g} / \mathrm{h} / \mathrm{cm}^{2}$ of the measured sample.

The moisture transfer itself takes place in two areas. From the aquarium with $100 \%$ relative humidity to the lower edge of the measured sample, from there through the sample itself to the upper surface and from there to the surrounding air.

Permeability can be calculated according to [31]:

$$
\mathrm{Per}_{\text {air }}=\frac{\dot{m}}{P_{\text {sat }}\left(R \cdot H_{\text {in }}-R \cdot H_{\text {nut }}\right)}
$$

Air resistance to moisture transfer is calculated according to (Cengel [32]):

Where:

$$
R_{\text {air }}=\frac{1}{\text { Per }_{\text {nir }}}
$$

$\begin{array}{ll}\text { Per }_{\text {air }} & : \text { Air permeability, } \mathrm{kg} /\left(\mathrm{m}^{2} \cdot \mathrm{s} \cdot \mathrm{Pa}\right) \\ \mathrm{P}_{\text {Sat }} & : \text { Saturation pressure, } \mathrm{Pa} \\ \dot{\mathrm{m}} & : \text { Transferred moisture, }\left(\mathrm{kg} / \mathrm{m}^{2} \cdot \mathrm{s}\right) \\ \mathrm{R} & : \text { Sample resistance to moisture transfer, } \mathrm{m}^{2} \cdot \mathrm{s} / \mathrm{kg} \\ \mathrm{R}_{\text {air }} & : \text { Air resistance to moisture transfer, } \mathrm{m}^{2} \cdot \mathrm{s} \cdot \mathrm{Pa} / \mathrm{kg} \\ \mathrm{H} & : \text { Enthalpy, } \mathrm{J} / \mathrm{kg}\end{array}$

\section{Description}

Various materials were measured. A total of twelve samples were used for the measurement. Out of these, the focus is on three, for which there are the most documented individual measurements, which took place after the elimination of deficiencies in the measuring set and in the measurement and evaluation procedure. The whole process of measuring the vapor permeability of materials has gradually evolved; hence the results are more accurate towards the end of the recorded measurements. With regard to trademarks of industrial property, only the composition or a general description of individual materials is mentioned. As we do not have the permission of individual manufacturers, the names of the materials are intentionally not specified to avoid violation of industrial property laws. 


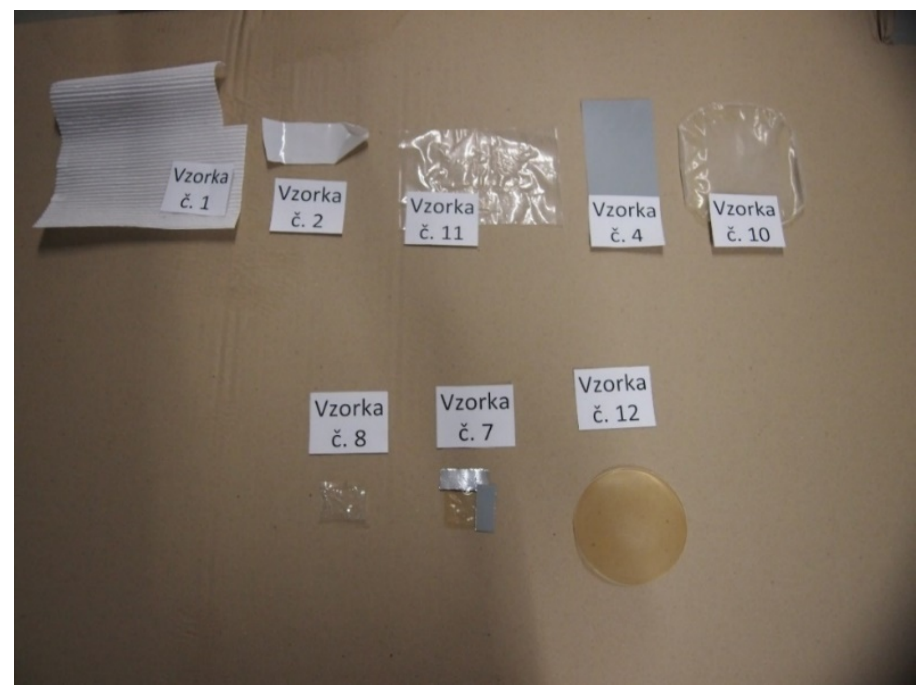

Figure 3: A photo of all measured samples

\subsection{Sample No. 1}

A piece of special patented paper, which has now been used in the production of enthalpy exchangers that allow both heat and moisture recovery for a long time. It serves as a comparison sample of the current functional material with new materials. This material is evaluated in this research paper.

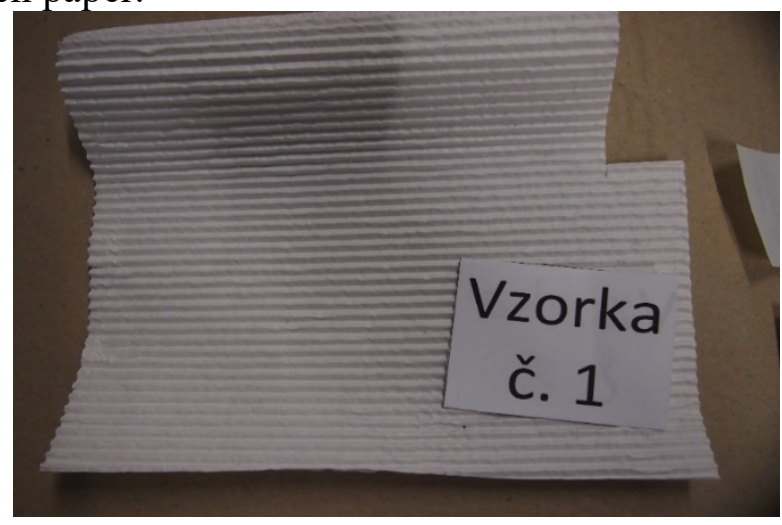

Figure 4: Sample No. 1

\subsection{Sample No. 2}

It is a "semi-permeable membrane based on cross-linked polymer". This material is evaluated in the research paper. 


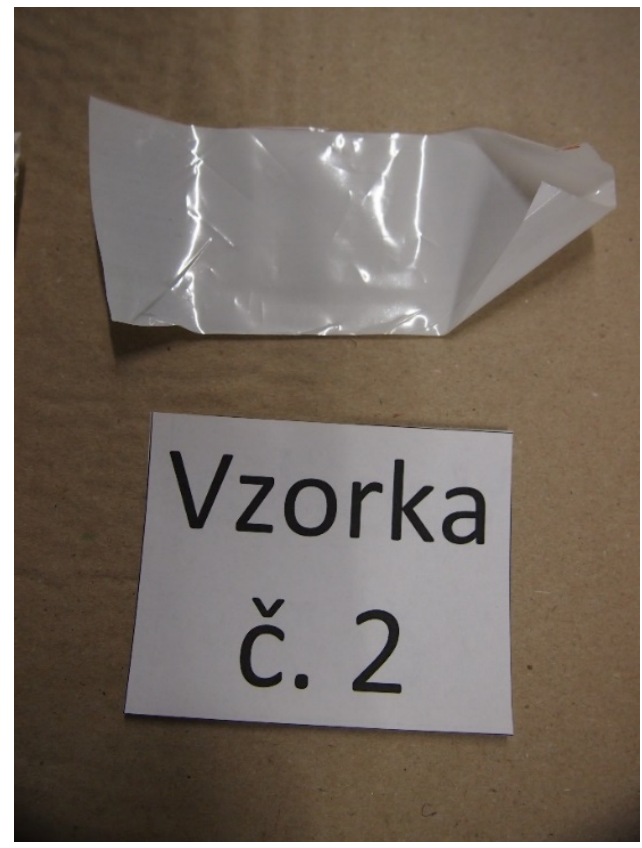

Figure 5: Sample No. 2

\subsection{Sample No. 3, 5, 6, 10, 11}

Different types and thickness of thermoplastic elastomer. This material is evaluated in the research paper.

\subsection{Sample No. 4}

The existing hPS Atrea material currently used to make standard heat recovery exchangers without moisture recovery - it was used to test the tightness of the measuring set.

\subsection{Sample No. 7, 8, 9}

It is a "semi-permeable membrane based on cross-linked polymer". This material is evaluated in the research another type of the sample no. 2 of different thickness. It is a "semi-permeable membrane based on a cross-linked polymer". This material is not evaluated in the work.

\subsection{Sample No. 12}

Copolymer resin. This material is evaluated in the work.

\subsection{Measuring protocols}

Due to the number of repeated measurements, samples no. 1, 2 and 12 were evaluated. Sample no. 4 served to continuously eliminate leaks and shortcomings of the measuring set since it is a material which is vapor-tight. 
A measurement protocol was prepared for each measurement. The measurement protocol for the evaluated samples contains:

- Measurement date

- Start of measurement

- Initial assembly weight

- End of measurement

- Final assembly weight

- Steady water temperature

- Steady temperature inside the aquarium

- Relative humidity in the aquarium (assumption 100\%)

- Absolute humidity inside the aquarium

- Ambient temperature

- Steady relative ambient humidity

- Absolute ambient humidity

- The difference between the absolute humidity in the aquarium and the absolute ambient humidity

- Permeability

- Sample area

- Specific permeability

- A note 


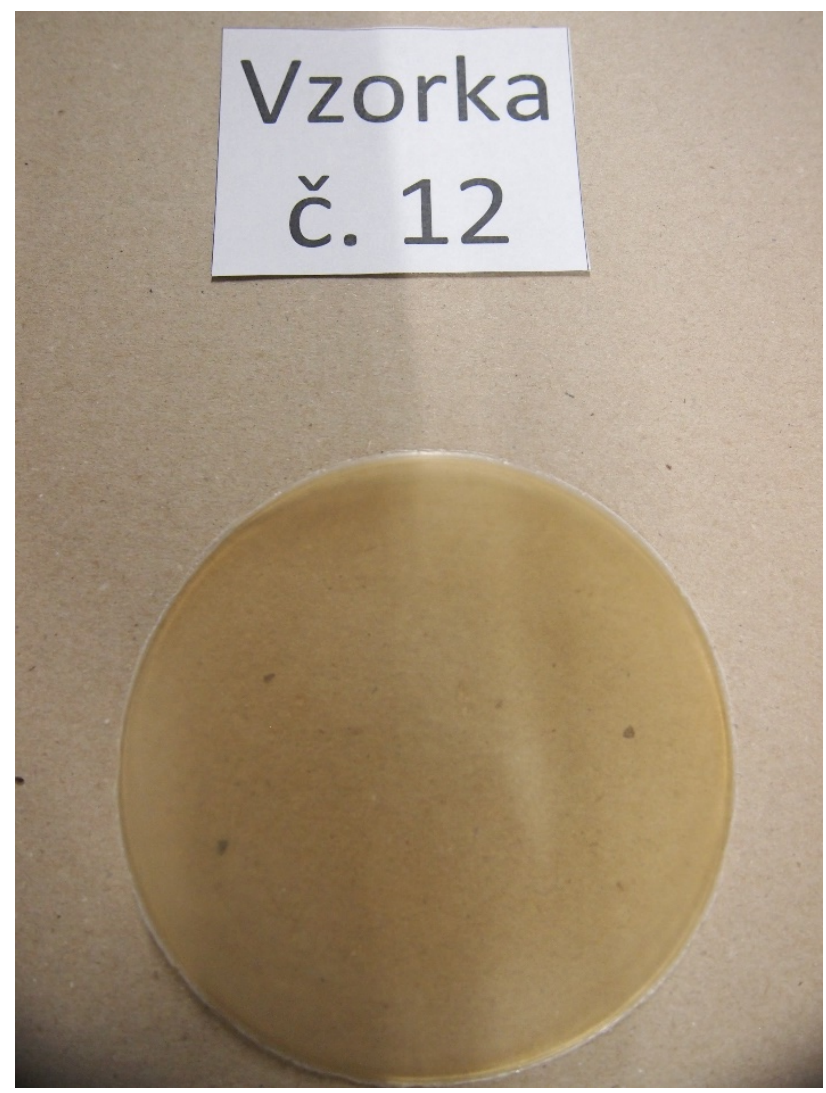

Figure 6: Sample No. 12

\section{Evaluation}

Out of the total number of 47 measurements during the entire period of one year, a total of eleven measurements of 3 measured samples (no. 1, 2 and 12) were evaluated. These measurements were purposefully selected as the least affected by the error rate and by the gradual improvement of the measuring set. Individual descriptions of the measuring set modifications as well as control measurements with the sample no. 4, or repeated measurements are stated in individual measurement protocols. Because the heater in the aquarium was just a common one, there were inexplicable fluctuations in water temperature, $+/-1{ }^{\circ} \mathrm{C}$. Thus, the measurement is affected by this deviation. However, in the long run, all measured samples had the same conditions, therefore, this error can be accepted. It does not affect the comparison of the specific permeability of water vapor significantly. At the beginning of the measurements, experiments were made with changing the water temperature as the "driving force" of the whole process, but these changes did not have a significant effect on the results, so the results were accepted with this inaccuracy. In the end it turned out that these fluctuations are caused by the thermostat in the heater device itself, and the temperature has since been additionally controlled by an immersion thermometer attached to the wall of the aquarium.

Another disadvantage of the measuring apparatus was the assumed leak, therefore, at the beginning of the measurements a value of $0.1 \mathrm{~g} / \mathrm{h}$ was deducted from the value of water vapor 
permeability. This leak also appeared in the leak test.

Gradual improvement of the measurement procedure, however, showed that the problem was not in the leakage of the measuring apparatus itself, but in the repeated weighing of the measured sample on the scale SOEHNLE QC Page Profi No. 67080. The scale was calibrated in 02/2018. For the first measurements, the assembly was weighed once, after the water level had completely stabilized on the scale. Then, however, the assembly was weighed ten times at the beginning of the measurement as well as at the end of the measurement. From these values, an arithmetic average was calculated. Its value was entered in the protocol as well as in the table, as the weight at the beginning and end of the measurement. In this way, a deviation in the measurements of $+/-$ $1 \mathrm{~g}$ from the total weight of the weighed assembly, which was found in later measurements, was excluded. As a result, the value of $0.1 \mathrm{~g} / \mathrm{h}$ was no longer deducted from the water vapor permeability.

Each measurement was performed in the same given manner described above.

The result of the measurements determines the specific water vapor permeability of the individual assessed samples and their mutual comparison in tables and graphs.

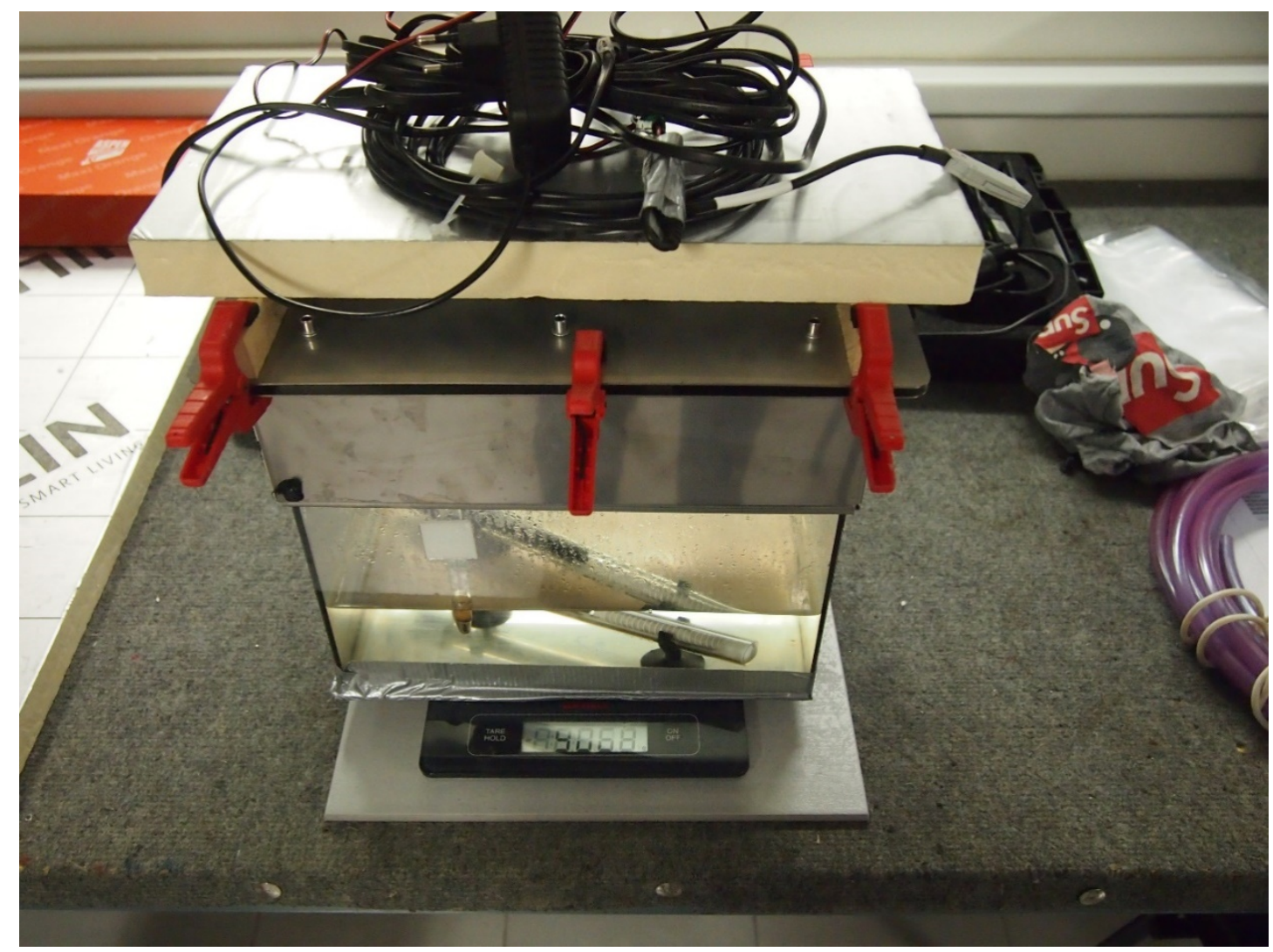

Figure 7: A photo of the measuring set while being weighed at the beginning of the measurement

Table 1: Measured and calculated data from the measurements

\begin{tabular}{|l|c|c|c|c|c|c|c|c|c|c|c|}
\hline $\begin{array}{l}\text { Measurement } \\
\text { date }\end{array}$ & 17.2. & 11.3. & 13.3. & 20.3. & 27.3. & 1.6. & 2.6. & 3.6. & 19.6. & 26.6. & 28.6 \\
\hline $\begin{array}{l}\text { Measurement } \\
\text { number }\end{array}$ & 27 & 29 & 30 & 32 & 34 & 43 & 44 & 45 & 46 & 47 & 48 \\
\hline Material & Sample & Sample & Sample & Sample & Sample & Sample & Sample & Sample & Sample & Sample & Sample no. 12 \\
\hline
\end{tabular}




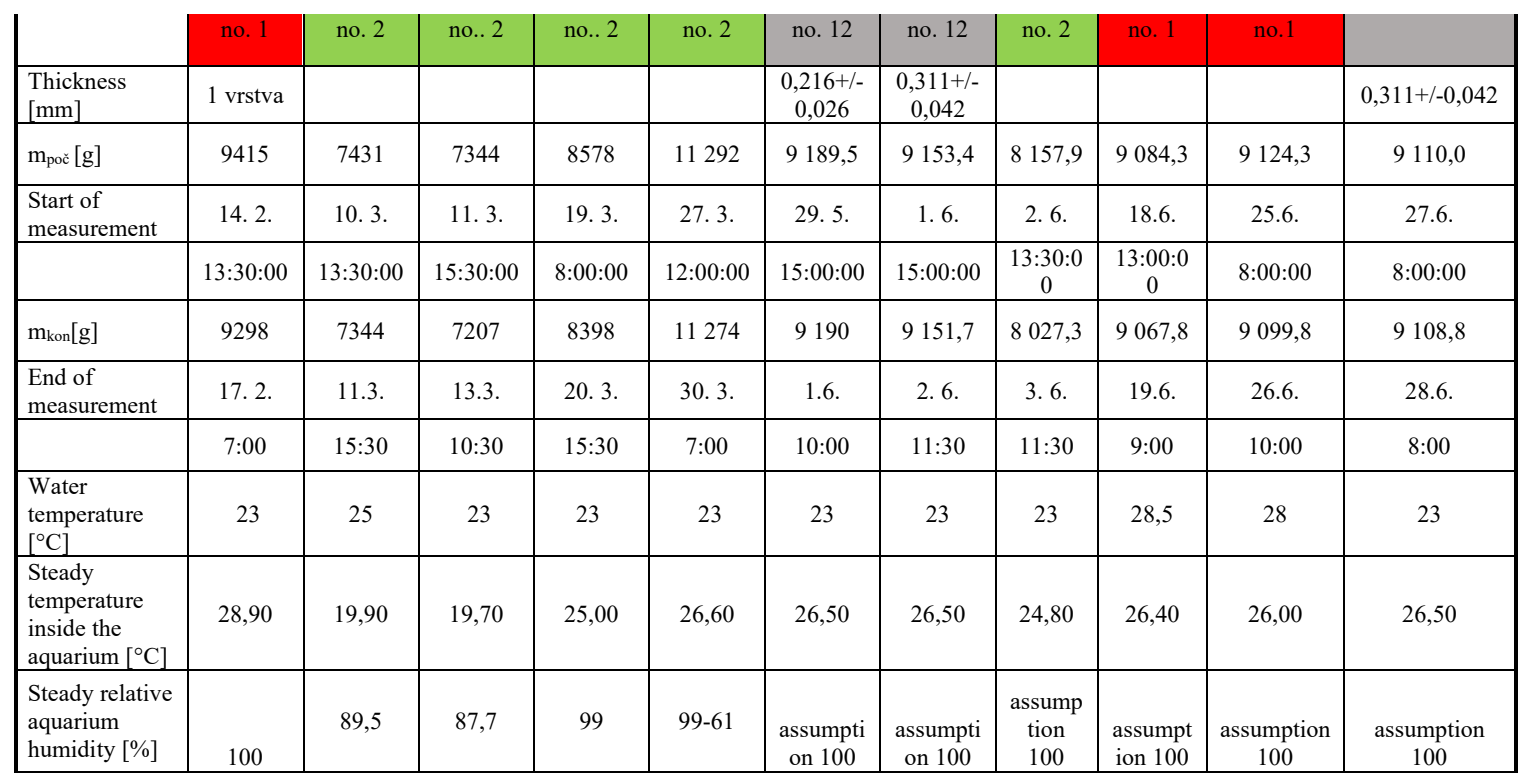

Table 1: Measured and calculated data from the measurements (cont.)

\begin{tabular}{|l|c|c|c|c|c|c|c|c|c|c|c|}
\hline \multicolumn{10}{|c|}{ Measured and calculated data from the measurements (cont.) } \\
\hline $\begin{array}{l}\text { Measurement } \\
\text { date }\end{array}$ & 17.2. & 11.3. & 13.3. & 20.3. & 27.3. & 1.6. & 2.6. & 3.6. & 19.6. & 26.6. & 28.6 \\
\hline $\begin{array}{l}\text { Measurement } \\
\text { number }\end{array}$ & 27 & 29 & 30 & 32 & 34 & 43 & 44 & 45 & 46 & 47 & 48 \\
\hline Material & $\begin{array}{c}\text { Sample } \\
\text { no. } 1\end{array}$ & $\begin{array}{c}\text { Sample } \\
\text { no. 2 }\end{array}$ & $\begin{array}{c}\text { Sample } \\
\text { no.. 2 }\end{array}$ & $\begin{array}{c}\text { Sample } \\
\text { no.. 2 }\end{array}$ & $\begin{array}{c}\text { Sample } \\
\text { no. 2 }\end{array}$ & $\begin{array}{c}\text { Sample } \\
\text { no. 12 }\end{array}$ & $\begin{array}{c}\text { Sample } \\
\text { no. 12 }\end{array}$ & $\begin{array}{c}\text { Sample } \\
\text { no. 2 }\end{array}$ & $\begin{array}{c}\text { Sample } \\
\text { no. 1 }\end{array}$ & $\begin{array}{c}\text { Sample } \\
\text { no.1 }\end{array}$ & Sample no. 12 \\
\hline $\begin{array}{l}\text { Absolute } \\
\text { humidity in } \\
\text { aquarium } \\
\text { [g/kg] }\end{array}$ & 26,11 & 13,2 & 12,9 & 20 & 24 & 22,6 & 22,6 & 20,3 & 22,4 & 21,9 & 22,6 \\
\hline $\begin{array}{l}\text { Ambient } \\
\text { temperature } \\
{\left[{ }^{\circ} \mathrm{C}\right]}\end{array}$ & 22,5 & 22,5 & 22,3 & 22 & 22 & 22,6 & 22,3 & 22,6 & 23,3 & 22,5 & 22,8 \\
\hline $\begin{array}{l}\text { Steady relative } \\
\text { ambient } \\
\text { humidity [\%] }\end{array}$ & 48,3 & 29 & 35 & 36 & 26 & 41,3 & 46,6 & 46 & 49,4 & 50,1 & 47,5 \\
\hline $\begin{array}{l}\text { Absolute } \\
\text { ambient } \\
\text { humidity } \\
\text { [g/kg] }\end{array}$ & 8,4 & 4,9 & 6 & 6,1 & 4,5 & 7 & 7,8 & 8 & 9 & 8,7 & 8,4 \\
\hline $\begin{array}{l}\text { Difference } \\
\text { absolute } \\
\text { humidity } \\
{[\mathrm{g} / \mathrm{kg}]}\end{array}$ & 17,71 & 8,3 & 9,7 & 13,9 & 19,5 & 15,6 & 14,8 & 12,3 & 13,4 & 13,2 & 14,2 \\
\hline $\begin{array}{l}\text { Permeability } \\
\text { [g/h] }\end{array}$ & 1,79 & 3,3 & 3,2 & 7,8 & 0,27 & 0 & 0,083 & 5,94 & 0,825 & 0,946 & 0,05 \\
\hline $\begin{array}{l}\text { Sample } \\
\left.\text { area[cm }{ }^{2}\right]\end{array}$ & 97,7 & 594,5 & 594,5 & 594,5 & 13,5 & 0 & 78,5 & $\mathrm{z}$ & 78,5 & 78,5 & 78,5 \\
\hline $\begin{array}{l}\text { Specific } \\
\text { permeability } \\
\left.\text { [g/h-cm }{ }^{2}\right]\end{array}$ & 0,018 & 0,006 & 0,005 & 0,013 & 0,020 & 0 & 0,0011 & 0,01 & 0,011 & 0,012 & 0,0006 \\
\hline
\end{tabular}

Based on the measured data, five dependencies which are being compared are determined:

- Dependency of specific permeability on the temperature inside the aquarium

- $\quad$ Dependency of specific permeability on the ambient temperature

- Dependency of specific permeability on the difference of absolute humidity's

- $\quad$ Dependency of specific permeability on the temperature difference

- Dependency of specific permeability on the amount of measurement time 


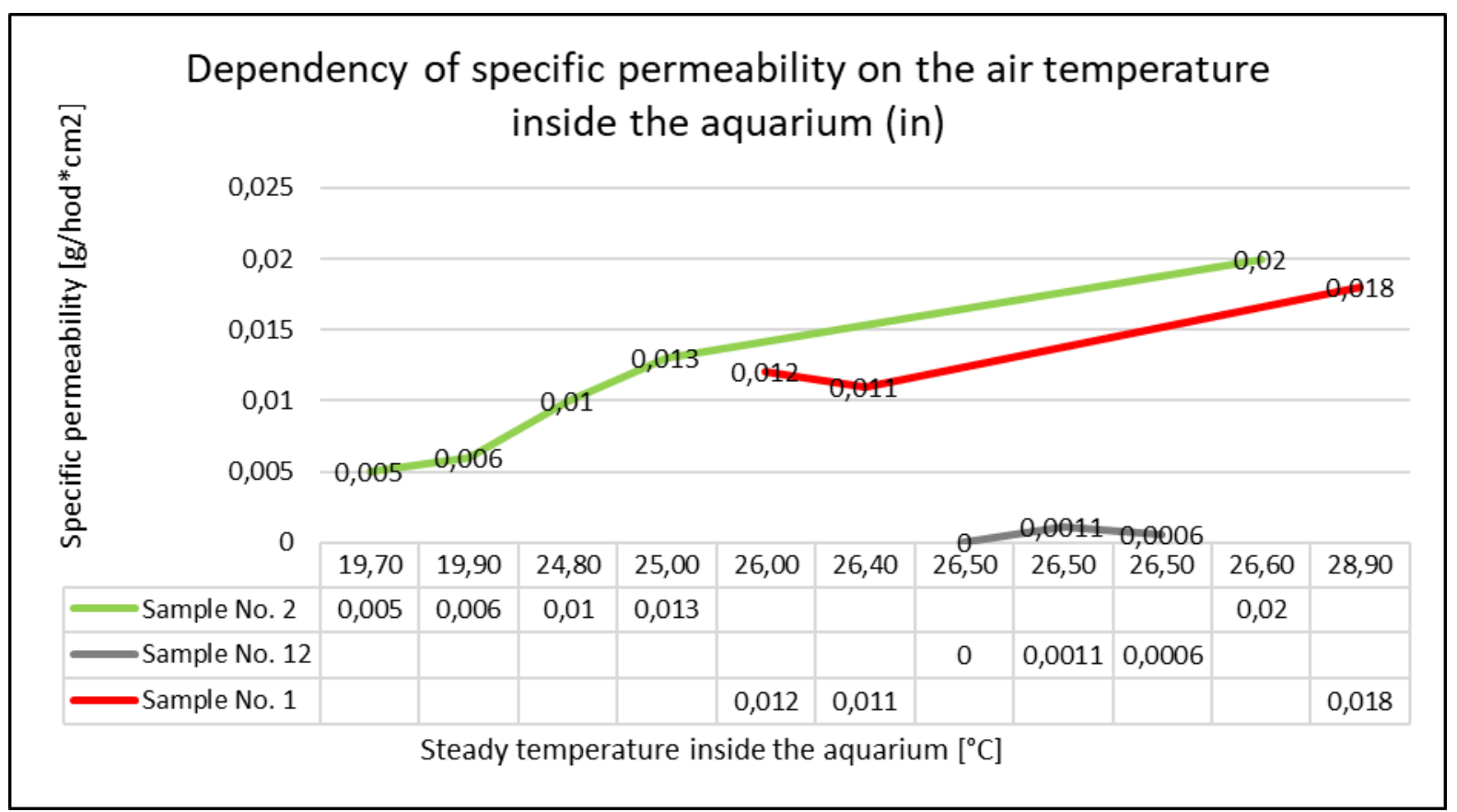

Figure 8: Dependency of specific permeability on the temperature inside the aquarium (in)

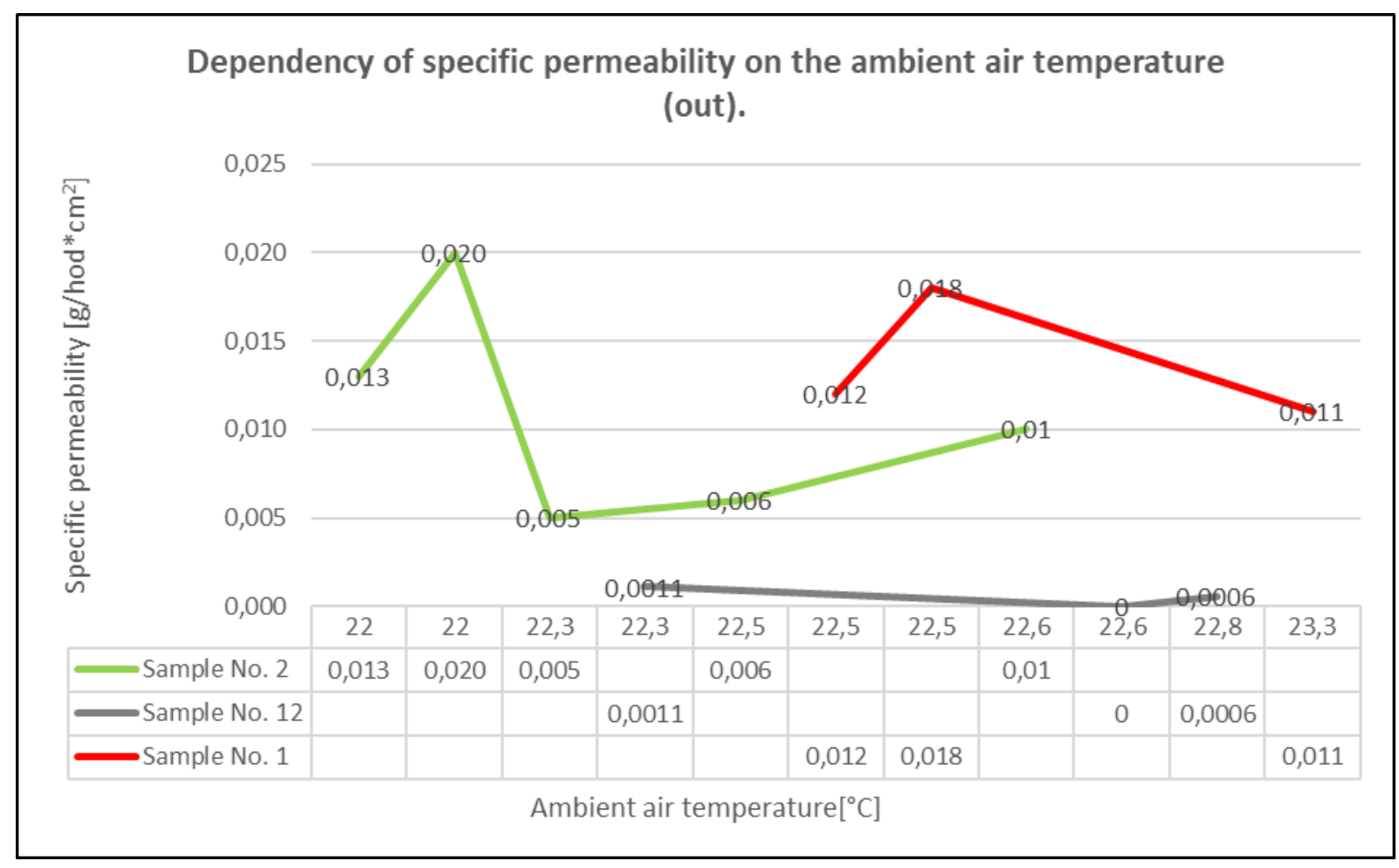

Figure 9: Dependency of specific permeability on the ambient temperature (out) 


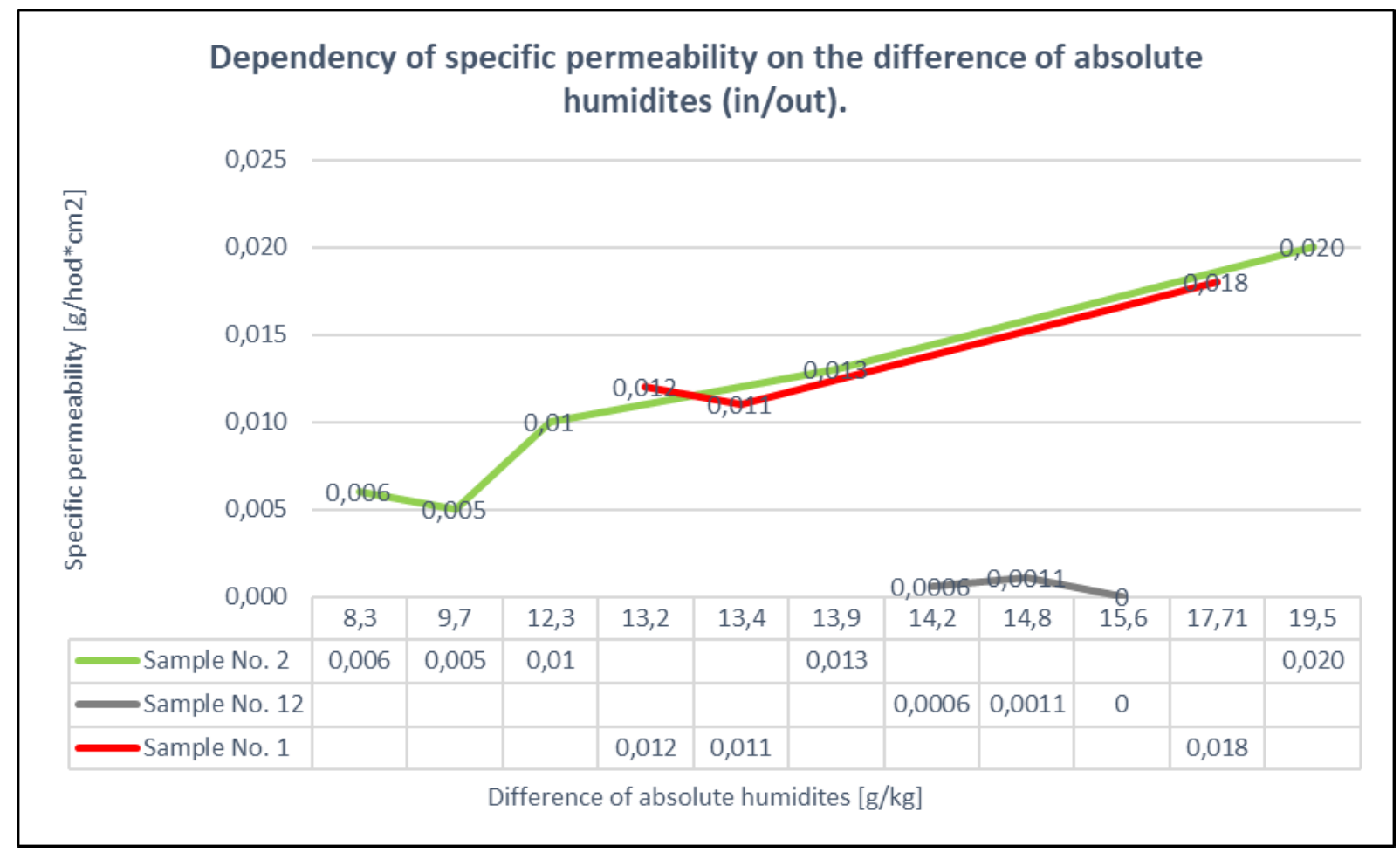

Figure 10: Dependency of specific permeability on the difference of absolute humidity's (in/out)

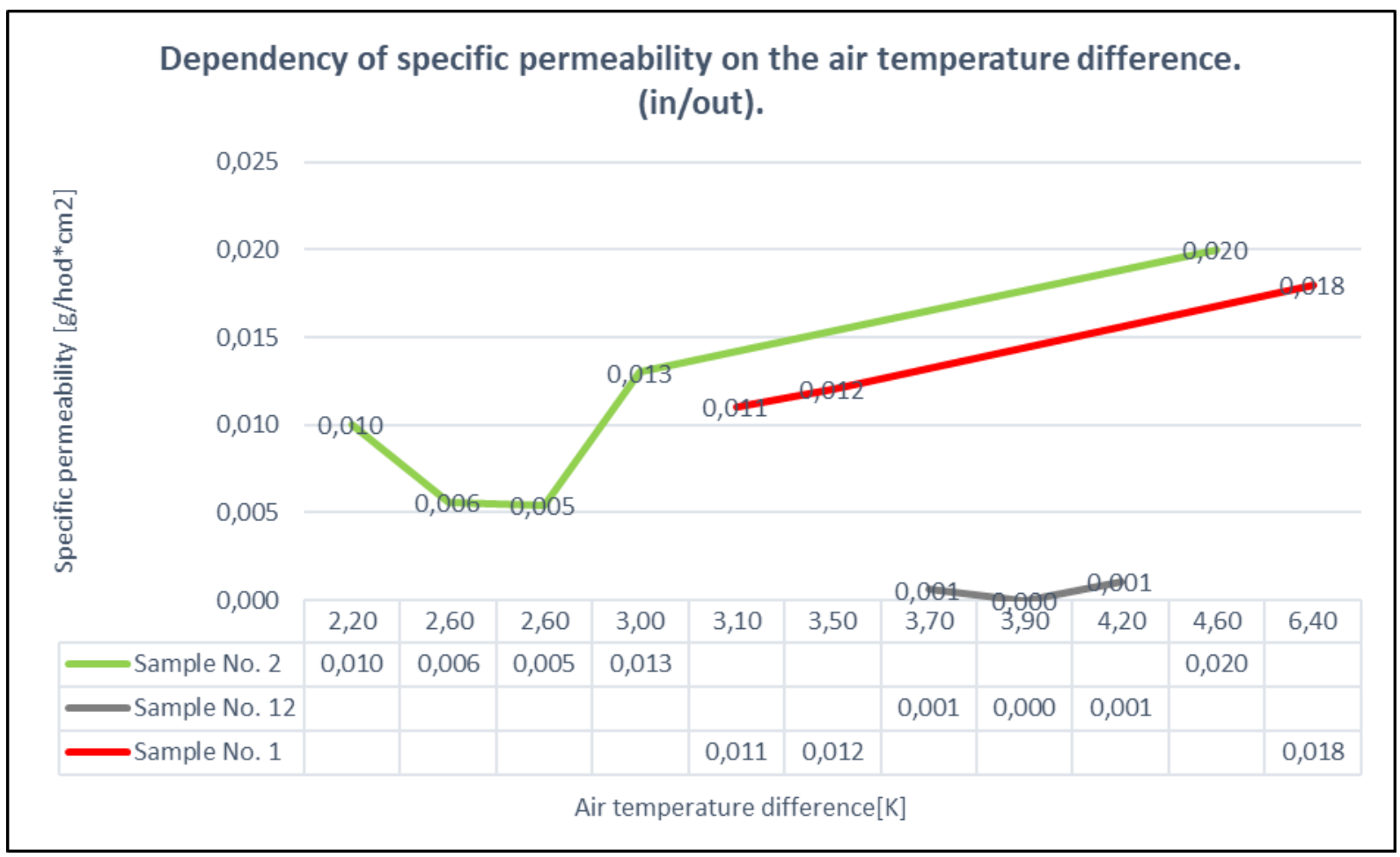

Figure 11: Dependency of specific permeability on the air temperature difference. (in/out) 


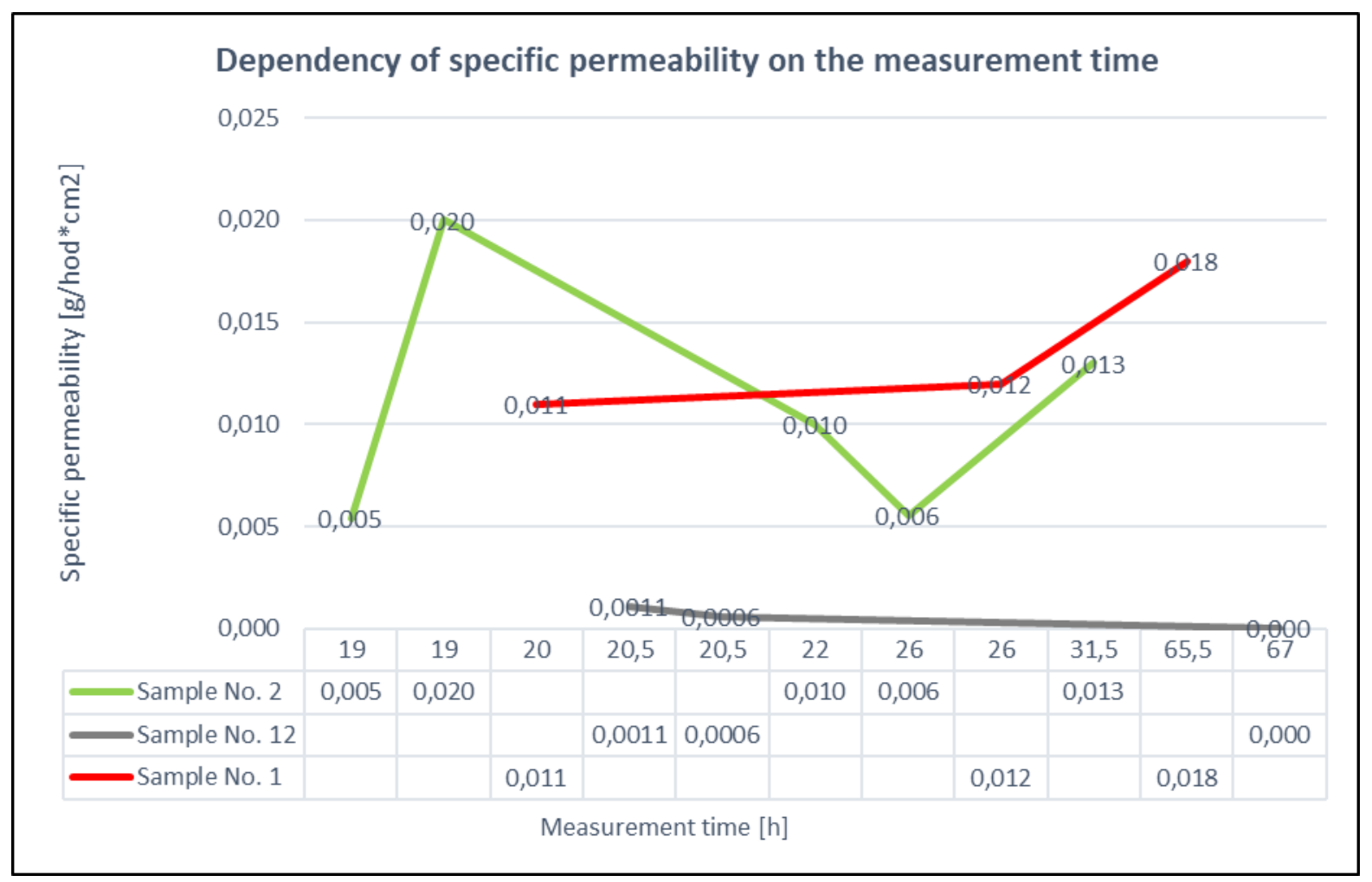

Figure 12: Dependency of specific permeability on the measurement time

The above graphs show that the highest specific permeability of water vapor is achieved by the sample no. 2 - whether concerning the dependency on the air temperature in the aquarium or on the ambient air temperature, and also on the difference in the absolute humidity's. However, the afore-mentioned material has the least prerequisites for use due to poor mechanical properties. In contrast, the material of the sample no. 12, which was assumed to be suitable for use, either from a mechanical or chemical point of view, had the most unfavorable parameters of all three evaluated samples.

The main idea of the measurements was to look for alternative materials for enthalpy exchangers, (heat exchangers capable of transmitting not only thermal energy, but also moisture) and subsequently to look for their use in ventilation and air conditioning systems. The benefit in our contribution is that the materials that are examined and compared are normally not usable/used for this purpose, i.e. according to the available sources, no one has yet explored their use in ventilation and air conditioning systems. Similar materials have been researched in [31]. This is also one of the reasons for not giving the names of individual materials. Therefore, only their general description or general chemical composition is mentioned, and all the materials are marked as a sample number $1-12$. This was the reason for the chosen methodology of comparison with an already existing material, which has been used in the production of heat and moisture recovery exchangers the longest time. This specific method of mutual comparison makes it easy and realistic to compare the specific water vapor permeability of the individual materials.

Based on the specific permeability, we can determine, for instance, the size of the area of the enthalpy exchanger according to the parameters that are determined in advance (in this case it is how many grams of water vapor per hour needs to be transferred through the exchanger). 
Given that theoretically, there are many suitable materials for use in the production of heat exchangers that allow heat and moisture recovery, this research is in its infancy. The ways to implement these materials in ventilation and air conditioning systems are still being researched. Of course, it is possible to use other methodologies to compare materials. Nevertheless, this method appears to be quite reliable once the deficiencies (either due to their design or the measurement procedure itself) were gradually eliminated. The measuring set is portable and relatively easy to construct. This made it possible to perform many measurements at home. Hence it is possible to measure other types of materials and compare them with each other. The only condition is to have a calibrated measuring device for measuring temperature and humidity, and a calibrated weight. During the measurements, the afore-mentioned device AHLBORN ALMEMO 2690 was used with a temperature sensor in the space inside the aquarium because the combination temperature and humidity sensor (which also measured humidity) was repeatedly flooded at $100 \%$ relative humidity and caused errors in displaying the sensor values. Hence it was not possible to record relative humidity and the right temperature. The combination temperature sensor was used to measure the temperature and humidity around the measuring set.

Other components are common ones and were purchased in the aquarium shop. The components made of stainless steel such as the cover (the lid that covers the measuring set) were made by Atrea Company on a CNC machine.

\section{Conclusion}

This research paper does not address the construction of the exchanger itself, as this topic would need a separate assessment methodology. This research focuses only on finding new materials for use in this area. Each measured sample has specific chemical, mechanical and thermo-technical properties. According to the results of the measurements, some samples change their shape, they stretch, shrink, deform, or return to their original shape, which has a major impact on the mechanical construction of the exchanger and its subsequent use in real life. The solution, after selecting a suitable material, could be adding additional reinforcement materials for mechanical strength, which would minimally restrict the actual air flow and the transfer of water vapor, and they would also maintain the optimal size of the heat and moisture recovery exchanger. An important aspect is also the hygienic aspect, resulting from the transfer of water vapor, which has not been assessed and evaluated here. One of the partial results was the "onion test". It was experimentally performed during a long-term test on some samples, in which the transfer of odors through selected measured samples is monitored. This test was performed at Atrea company premises. In this case, instead of water, a pan with fried onions is placed in the aquarium, the measuring set is closed and transferred to another room where respondents answer whether and how they perceive the smell of the onion. The respondents compared several samples, and it was interesting to see their perception. In some cases, the respondents even smelled the technical smell of the film, which can have a significant impact on the actual use in practice. Of course, this is influenced by the air temperature in the assembly, which, after inserting the hot pan, reaches higher values than in the common practice in air handling units. These outputs are presented in individual measurement protocols and in the overall table where there is a record of all the measurements, even those that are not compared and evaluated in this research paper. There is a need for separate research on this topic concerning hygiene, which is 
also continuously processed and evaluated. An important finding was that the material that achieves the best results in water vapor transmission has the worst mechanical properties, when the future construction of an exchanger is considered. On the contrary, the material which was assumed to have excellent mechanical properties, and which was declared to have vapor permeable properties by the manufacturer, achieves the worst parameters of water vapor transmission. The research of water vapor transmission itself is not completed, as new materials are continuously made. Nevertheless, even the already existing materials such as, for example, the sample no. 12, are still being researched. We continue looking for their possible use, either by changing the thickness of the sample or its chemical composition, which would be able to increase the vapor permeability of the material itself. This currently limits it the most. With the sample no. 2, however, the problem is the opposite. More research on the mechanical properties of its material still needs to be conducted and a new way how to construct the exchanger needs to be found. Further research and evaluation criteria are needed in these areas; however, these are not addressed in this article.

\section{Funding:}

This work was financially supported by the Grant Agency of Slovak Republic to support project No. VEGA 1/0512/20: "Analysis of new approaches and certification of sustainable office buildings from the perspective of wellbeing and performance of employees."

\section{References}

[1] Directive of the European Parliament. (2018). Directive (EU) 2018/844 of the European Parliament and of the Council of 30 May 2018 amending Directive 2010/31/EU on the energy performance of buildings and Directive 2012/27/EU on energy efficiency. Available online: http://data.europa.eu/eli/dir/2018/844/oj (acces 10. october 2020).

[2] Airaksinen, M. (2011). Energy Use in Day Care Centers and Schools. Energies 2011, 4, 9981009.

[3] Steen Englund, J.; Cehlin, M.; Akander, J.; Moshfegh, B. (2020).Measured and Simulated Energy Use in a Secondary School Building in Sweden-A Case Study of Validation, Airing, and Occupancy Behaviour. Energies 2020, 13, 2325.

[4] Wahid, F.; Fayaz, M.; Aljarbouh, A.; Mir, M.; Aamir, M.; Imran. (2020).Energy Consumption Optimization and User Comfort Maximization in Smart Buildings Using a Hybrid of the Firefly and Genetic Algorithms. Energies 2020, 13, 4363.

[5] Ruiz, G.R.; Bandera, C.F. (2017). Validation of Calibrated Energy Models: Common Errors. Energies 2017, 10, 1587.

[6] Wang, W.; Shan, X.; Hussain, S.A.; Wang, C.; Ji, Y. (2020). Comparison of Multi-Control Strategies for the Control of Indoor Air Temperature and CO2 with OpenModelica Modeling. Energies 2020, 13, 4425.

[7] Bahramnia, P.; Hosseini Rostami, S.M.; Wang, J.; Kim, G.-J. (2019).Modeling and Controlling of Temperature and Humidity in Building Heating, Ventilating, and Air Conditioning System Using Model Predictive Control. Energies 2019, 12, 4805. 
[8] Dall'O', G.; Belli, V.; Brolis, M.; Mozzi, I.; Fasano, M. (2013). Nearly Zero-Energy Buildings of the Lombardy Region (Italy), a Case Study of High-Energy Performance Buildings. Energies 2013, 6, 3506-3527.

[9] Cho, K.; Cho, D.; Kim, T. (2020). Effect of Bypass Control and Room Control Modes on Fan Energy Savings in a Heat Recovery Ventilation System. Energies 2020, 13, 1815.

[10] Bendic, V.; Dobrotă, D. (2018). Theoretical and Experimental Contributions on the Use of Smart Composite Materials in the Construction of Civil Buildings with Low Energy Consumption. Energies 2018, 11, 2310.

[11] The European parliament (2019) COMMUNICATION FROM THE COMMISSION TO THE EUROPEAN PARLIAMENT, THE EUROPEAN COUNCIL, THE COUNCIL, THE EUROPEAN ECONOMIC AND SOCIAL COMMITTEE OF THE REGIONS: The European Green Deal. COM/2019/640. https://eur-lex.europa.eu/legal-content/EN/TXT/?uri=COM:2019:640:FIN

[12] Available online: https://ourworldindata.org/co2/country/bhutan?country= BTN.

[13] European Commission's. (2014). European Commission's regulation No. 1253/2014 from 7 July 2014, implementing the directive 2009/125/ES of the European Parliament and of the Council [3] concerning the eco-design of ventilation units. Available online: https://eurlex.europa.eu/legal-content/GA/TXT/?uri=CELEX\%3A32014R1253

[14] Ding, Z.; Liu, R.; Li, Z.; Fan, C. A (2020). Thematic Network-Based Methodology for the Research Trend Identification in Building Energy Management. Energies 2020, 13, 4621.

[15] Rosato, A.; Guarino, F.; Filomena, V.; Sibilio, S.; Maffei, L. (2020). Experimental Calibration and Validation of a Simulation Model for Fault Detection of HVAC Systems and Application to a Case Study. Energies 2020, 13, 3948.

[16] Dong, J.; Winstead, C.; Nutaro, J.; Kuruganti, T. (2018). Occupancy-Based HVAC Control with Short-Term Occupancy Prediction Algorithms for Energy-Efficient Buildings. Energies 2018, 11, 2427.

[17] Kim, N.-K.; Shim, M.-H.; Won, D. (2018). Building Energy Management Strategy Using an HVAC System and Energy Storage System. Energies 2018, 11, 2690.

[18] Kassai, M.; Al-Hyari, L. (2019). Investigation of Ventilation Energy Recovery with Polymer Membrane Material-Based Counter-Flow Energy Exchanger for Nearly Zero-Energy Buildings. Energies 2019, 12, 1727.

[19] Zhang, L.; Zhang, Y.F. (2016). Research on Heat Recovery Technology for Reducing the Energy Consumption of Dedicated Ventilation Systems: An Application to the Operating Model of a Laboratory. Energies 2016, 9, 24.

[20] Zhang, L.; Zhang, Y.-F. (2014). Research on Energy Saving Potential for Dedicated Ventilation Systems Based on Heat Recovery Technology. Energies 2014, 7, 4261-4280.

[21] De Antonellis, S.; Intini, M.; Joppolo, C.M.; Leone, C. (2014). Design Optimization of Heat Wheels for Energy Recovery in HVAC Systems. Energies 2014, 7, 7348-7367.

[22] Al-Hyari, L ; Kassai, M. (2020). Development and Experimental Validation of TRNSYS Simulation Model for Heat Wheel Operated in Air Handling Unit. Energie 2020, 13, 4957.

[23] Fanger, P.O. (1970). Thermal comfort. Analysis and applications in environmental engineering. In Thermal Comfort. Analysis and Applications in Environmental Engineering. Danish Technical Press: Copenhagen, Denmark.

[24] Gładyszewska-Fiedoruk, K.; Zhelykh, V.; Pushchinskyi, A. (2019). Simulation and Analysis of 
Various Ventilation Systems Given in an Example in the Same School of Indoor Air Quality. Energies 2019, 12, 2845.

[25] Mjörnell, K.; Johansson, D.; Bagge, H. (2019).The Effect of High Occupancy Density on IAQ, Moisture Conditions and Energy Use in Apartments. Energies 2019, 12, 4454.

[26] Chyský, J., and K. Hemzal. (1993). Větrání a klimatizace.Bolit.

[27] Székyová, Marta, Karol Ferstl, and Richard Nový. (2004). Vetranie a klimatizácia. Jaga group.

[28] Vyhláška Ministerstva zdravotníctva Slovenskej republiky č. 259/2008 Z. z. o podrobnostiach o požiadavkách na vnútorné prostredie budov a o minimálnych požiadavkách na byty nižšieho standardu a na ubytovacie zariadenia. (č. 210/2016 Z. z., 124/2017 Z. z.). Official publication: Zbierka zákonov SR; Number: 105; Publication date: 17/07/2008

[29] Recknagel, Sprenger, Schramek. (1997).Taschenbuch für Heizung + Klimatechnik. 67. vydanie.

[30] ASTME96. (2000).American Standard Test Methods for Water Vapor Transmission of Materials, American Society for Testing and Materials, pp. 842-849.

[31] Nasif, Mohammad Shakir, Graham L. Morrison, and Masud Behnia. (2005). Heat and mass transfer in air to air enthalpy heat exchangers." Proceedings of the 6th World Conference on Experimental Heat Transfer, Fluid Mechanics, and Thermodynamics. Matsushima, Japan.

[32] Yunus A. Çengel, Afshin J. Ghajar. (2011). Heat and mass transfer fundamentals and applications. McGraw-700 Hill Education 701. 52.

[33] Koester S.M., (2016). Membrane-based Enthalpy Exchagers, Von der Fakult"at fur Maschinenwesen " der Rheinisch-Westf"alischen Technischen Hochschule Aachen zur Erlangung des akademischen Grades eines Doktors der Ingenieurwissen schaften genehmigte Dissertation. 